Research Article

\title{
Combined Effect of Stray Current and Sustained Compressive Loading on Chloride Transport in Concrete
}

\author{
Yuancheng Ni and Eryu Zhu iii \\ School of Civil Engineering, Beijing Jiaotong University, Beijing 100044, China \\ Correspondence should be addressed to Eryu Zhu; 15115260@bjtu.edu.cn
}

Received 22 March 2021; Revised 29 June 2021; Accepted 2 July 2021; Published 25 September 2021

Academic Editor: Daniela Pilone

Copyright (C) 2021 Yuancheng $\mathrm{Ni}$ and Eryu Zhu. This is an open access article distributed under the Creative Commons Attribution License, which permits unrestricted use, distribution, and reproduction in any medium, provided the original work is properly cited.

\begin{abstract}
As with the leakage of stray current in the surrounding medium, the chloride transport in concrete is influenced by the stray current and loading of the subway structure. This paper presents the results of the experimental study on the chloride transport properties of concrete under the combined action of stray current and sustained compressive loading. First, an experiment was setup to explore the chloride transport in the subway structure as the concrete specimen embedded with steel under test current and study the influence of the existence of steel on the chloride transport profiles in concrete under stray current. Then, to investigate the combined effect of stray current and loading on the chloride transport properties, an improved experiment was designed with stray current and sustained compressive loading. The chloride transport profiles were measured, respectively, subjected to different stray currents and compressive stress levels. The experimental results indicated that stray current and sustained compressive loading have a significant influence on the chloride transport properties of concrete, and the loading threshold existed as the turning point of the chloride transport rate. Based on the experimental data and migration theory, the prediction model of chloride transport in concrete under stray current and sustained compressive loading was established and verified by the experimental measurements, and the steel corrosion-induced cover cracking was studied, and the comparison indicated that the numerical results were consistent with the experimental results.
\end{abstract}

\section{Introduction}

During the operation of subways, the insulation between the rail and the track bed is reduced, and the protective measures become invalid over time. Thus, the leakage of stray current to the surrounding medium is increased in the subway structures, especially for the DC (direct current) power supply system $[1,2]$. As we know, the presence of chlorides and their transport is a critical factor affecting the durability of reinforced concrete (RC) structures, which are increasingly decisive for the life cycle design of structures. For the subway structures, the chloride transport in concrete may be affected by stray current, which causes the steel corrosion in advance $[3,4]$, resulting in durability failure of the subway structure. In addition, the compressive loading on the structure may cause the occurrence and development of cracks in concrete, which also affect the chloride transport in concrete. Therefore, to evaluate the durability of the subway structures accurately, it is essential to consider the coupling effect of stray current and external loading on chloride transport in concrete.

Much work so far has focused on the chloride transport properties of concrete by using experimental, analytical, and numerical methods [5]. It was found that the transport properties of chloride in concrete depend largely on the transport channels (pore structure and micro cracks) [6]. Several reviews described Friedel's salt will be formed and precipitated in macropores when the chloride penetrates into the cement, thus reducing the number of macropores and changing the pore structure and distribution [7-9]. The bound chlorides in concrete could be released under the electric field, which significantly increased the concentration of the free chlorides $[10,11]$, and the external electric field accelerated the dissolution of $\mathrm{Ca}^{2+}$ in the pore solution of concrete [12]. The consequence of this chemical change was the decrease in 
TABLe 1: Mixture proportion of concrete $\left(\mathrm{kg} / \mathrm{m}^{3}\right)$.

\begin{tabular}{lccc}
\hline Cement & Water & Fine aggregate & Coarse aggregate \\
\hline 400 & 200 & 525 & 1355 \\
\hline
\end{tabular}

macropores and changes in the pore distribution [13], resulting in the degradation of concrete strength and elastic modulus at the macrolevel [14]. The effects of different water-cement ratios and admixtures on the pore structure and chloride transport properties of concrete were discussed [15].

In recent decades, extensive work has been carried on the prediction models of chloride transport under loading. However, there were few studies on chloride transport under sustained loading. As the damage of concrete under loading, the cracks developed in concrete, which caused the change of chloride diffusion in concrete $[16,17]$. The chloride transport properties were influenced by the crack performance of the concrete [18]. The ions' transport speed in the damage zones were much larger than those in the nondamage bulk mortar, and the chloride migration may be disrupted by dense array of multiple cracks [19]. Some authors pointed out that the change of chloride diffusion in concrete obtained by compressive loading showed a significant threshold effect on the experiments of the transport properties and cracks in concrete $[19,20]$. Other authors proposed that there was no significant threshold obtained in the experiments [21, 22]. Through detecting the instrument for concrete damage, some researchers evaluated the damage in concrete under uniaxial compressive loading and proposed the relationship between the loading and the chloride diffusion coefficient of concrete [23, 24].

Considerable research efforts have been devoted to the chloride penetration in concrete under the action of stray current and load, respectively. However, most corrosion tests did not consider the fact that the steel in the concrete as a carrier to transmit the current, which could attract the chloride ions to accumulate quickly near the anode. The mechanism of chloride transport in concrete under the combined action of stray current and compressive load is rarely studied. Specifically, in the absence of experimental data, the explanation for the chloride transport in subway structures has not yet been made clear.

The major objective of this study is to fill the gap by correlating the change in the chloride transport properties in concrete with stray current and sustained compressive loading. By the current test, considering the stray current flow in the steel in concrete, the changes of pore structure and chloride distribution of the concrete samples under different stray current conditions will be presented. Then, based on the test considering the coupling of compressive loading and stray current, the chloride distribution of the samples under different stray current and loading conditions will be presented, and the empirical quantitative relationship between chloride diffusivity and compressive stress levels will be developed. The model of chloride transport and cracking in concrete under stray current and compressive loading will be proposed, which can be used to illustrate the synergistic effect of stray current and loading on chloride transport in concrete.

\section{Materials and Methods}

2.1. Materials and Specimens. The cement used in this study was Ordinary Portland Cement (PO.42.5), which was produced in Shandong, China. The water/cement ratio was 0.5 . The fine aggregate used was a locally available sand with a fineness modulus of 2.40, and the coarse aggregate used was a locally available crushed gravel with the maximum size of $20 \mathrm{~mm}$ and density of $1355 \mathrm{~kg} / \mathrm{m}^{3}$. The details of concrete mixture proportions are presented in Table 1 .

The mixtures were cast into a mold with the dimensions of $150 \mathrm{~mm} \times 150 \mathrm{~mm} \times 150 \mathrm{~mm}$, and a steel with the diameter of $16 \mathrm{~mm}$ and the length of $300 \mathrm{~mm}$ was precast at the centre of the cross section. The specimens were cured under the condition that the temperature was $20^{\circ} \mathrm{C}$ and the relative humidity was over $90 \%$. After curing, five surfaces of the concrete specimens were sealed with epoxy resin to implement the one-dimensional penetration of chloride ions. The specimens were divided into series $S$ and series L. Series $S$ was used to investigate the influence of stray current through the steel on the chloride transport, and series L was used to investigate the influence of loading and stray current on the chloride transport.

2.2. Corrosion Test under Stray Current. The corrosion pool with a size of $2000 \mathrm{~mm} \times 2000 \mathrm{~mm} \times 300 \mathrm{~mm}$ was made by board. The waterproof cloth was placed in the pool to avoid the solution leakage. The temperature of the laboratory was set to $20^{\circ} \mathrm{C}$ to eliminate the influence of the temperature. According to GB/T 50082-2009 [25], the 5\% NaCl solution was used as the corrosion solution in the pool. Since the range of stray current in the subway was generally between $50 \mathrm{~mA}$ and $100 \mathrm{~mA}[26,27]$, the corrosion current used in this test was set as $50 \mathrm{~mA}$ and $100 \mathrm{~mA}$. The corrosion time used in this test was set as $1 \mathrm{~d}, 7 \mathrm{~d}$, and $14 \mathrm{~d}$. For the design of the corrosion test under stray current specimens, a group of five concrete specimens without current were placed in the corrosion pool as the reference group. The details of the corrosion test under stray current for the specimens are listed in Table 2.

The concrete specimens of Series $S$ were divided into 6 groups, as shown in Table 2. Each group was connected in series with the DC power. The power positive was connected to the steel bar, and the power negative was connected to the galvanized steel in the solution. The exposed steel of the specimen was wrapped with insulation tape to avoid the reaction to the external environment. The digital multimeter was used to check the continuity of the circuit. After the specimens were placed, the chloride solution was injected into the pool with the solution height of $40 \mathrm{~mm}$ to avoid direct contact with the steel. The experimental setup is shown in Figure 1. 
TABLE 2: Design of the corrosion test under stray current.

\begin{tabular}{lccc}
\hline Groups & Concentration (\%) & Current (mA) & Test time (day) \\
\hline S1-1 & & 50 & 1 \\
S1-2 & & 50 & 7 \\
S1-3 & 5 & 50 & 14 \\
S2-1 & & 100 & 1 \\
S2-2 & & 100 & 7 \\
S2-3 & & 100 & 14 \\
\hline
\end{tabular}

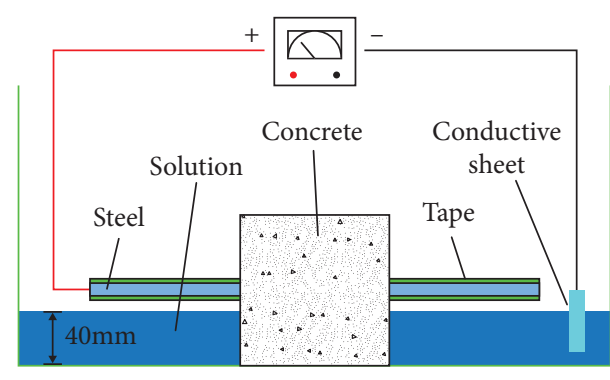

(a)

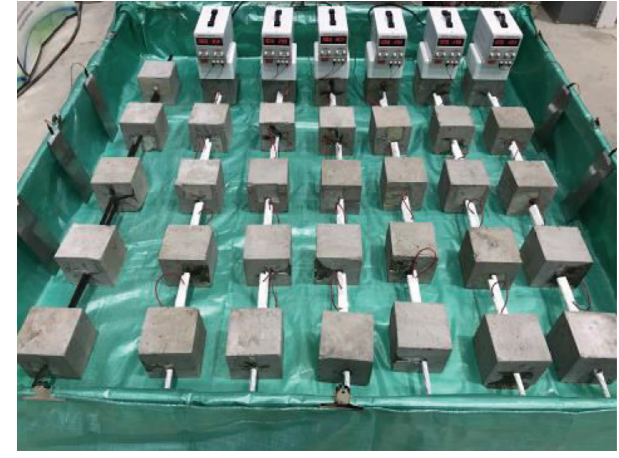

(b)

Figure 1: Setup for the corrosion test under stray current. (a) Test schematic. (b) Test process.

\subsection{Corrosion Test under Stray Current and Compressive} Loading. The test setup for the chloride transport under the combined action of compressive loading and stray current is shown in Figure 2. The device was composed of four parts: the corrosion box, the water-absorbing sponge, the conductive sheet, and the DC power. The application of the test load was controlled by a servo hydraulic loader. Five cube specimens were used to measure the average compressive ultimate strength as $23.56 \mathrm{MPa}$. The loading levels were designed as $0,10 \%, 30 \%$, and $50 \%$ of the compressive loading capacity of the cube specimen, respectively $\left(\lambda=\sigma_{\mathrm{c}} / f_{\mathrm{c}}\right)$. The corrosion current was set as $0 \mathrm{~mA}, 50 \mathrm{~mA}$, and $100 \mathrm{~mA}$, and the corrosion time was 1 day. The details of the corrosion test under stray current and compressive loading for the specimens for the specimens are shown in Table 3.

The test operation was briefly described as follows: the water-absorbent sponge in the test device was filled with $5 \% \mathrm{NaCl}$ solution. One side of the sponge was close to the specimen, and the other side was close to the conductive sheet. The power positive was connected to the steel in the concrete specimen, and the power negative was connected to the conductive sheet in the device. After the circuit was connected, the specimen was progressively loaded to reach the target stress level by the servo hydraulic loader. Then, the DC power was turned on to maintain the current at the target value. The specimens of Series $\mathrm{L}$ were tested under axial compressive loading and current conditions for 1 day.

2.4. Chloride Content Measurement. After the corrosion test, the concrete specimens were powdered by the grinding machine layer by layer from the exposed surface, and the thickness of each layer was controlled at $5 \mathrm{~mm}$, as shown in Figure 3. Then, the powder was passed through a sieve $(160 \mu \mathrm{m})$ and dried to a constant weight in a vacuum drying oven. After chemical titration with $\mathrm{AgNO}_{3}$, the chloride ion concentration was measured with the automatic potentiometric titrator (CT-1). According to GB/T 176-2017 [28], the mass percentage of chloride ion can be obtained by

$$
\omega_{C l^{-}}=\frac{T_{C l^{-}} \times\left(V_{1}-V_{2}\right) \times 0.1}{m},
$$

where $\omega_{\mathrm{Cl}^{-}}$is the mass fraction of chloride ion (\%), $T_{\mathrm{Cl}^{-}}$is the titer of the silver nitrate standard titration solution with chloride ion $(\mathrm{mg} / \mathrm{mL}), V_{1}$ is the volume of the silver nitrate standard titration solution consumed during titration $(\mathrm{mL})$, $V_{2}$ is the volume of the silver nitrate standard titration solution consumed when titrating blank $(\mathrm{mL})$, and $m$ is the quality of the sample (g). The Materials and Methods section should contain sufficient detail so that all procedures can be repeated. It may be divided into headed subsections if several methods are described.

\subsection{Measurement of Corrosion-Induced Crack and Steel Mass} Loss. Before the test, the specimen should be clean and checked whether there are initial cracks. After the test, the width and length of the crack can be measured with a crack observer and a ruler, and the crack parameters should be recorded step by step. Then, the steels were cleaned of corrosion and loosely-attached cement paste using a brush. The steels were dipped in a $10 \%$ ammonium citrate solution for $24 \mathrm{~h}$ to remove the corrosion products. The mass of steel was then measured to determine the final mass. The difference between the initial (before corrosion) and final (after 


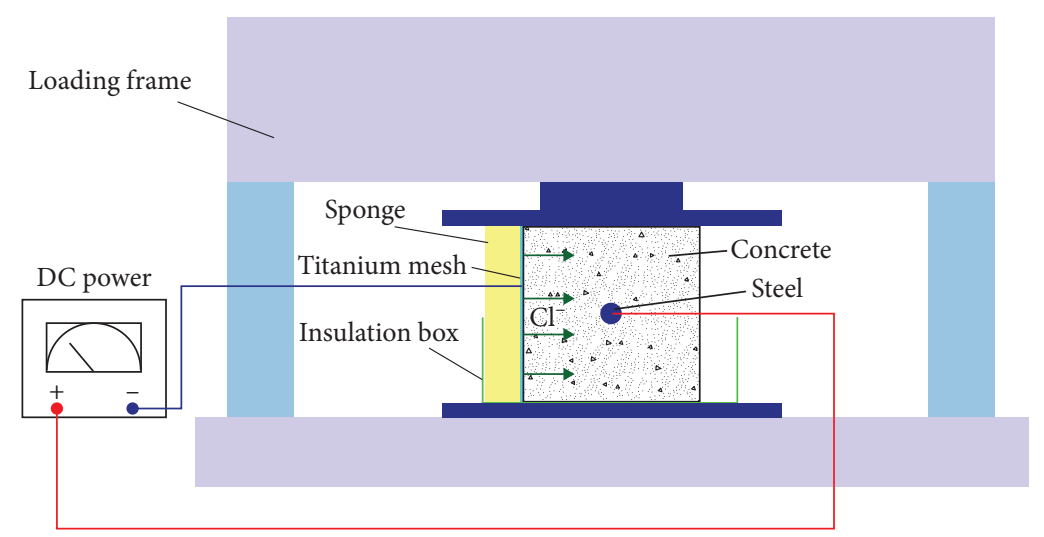

FIgURE 2: Setup for the corrosion test under stray current and compressive loading.

TABLE 3: Design of the corrosion test under stray current and compressive loading.

\begin{tabular}{lccc}
\hline Groups & Current $(\mathrm{mA})$ & Stress value $(\mathrm{MPa})$ & Stress level $(\%)$ \\
\hline L1-0 & 0 & 0 & 0 \\
L1-1 & 0 & 2.36 & 10 \\
L1-2 & 0 & 7.07 & 30 \\
L1-3 & 0 & 11.80 & 50 \\
L2-0 & 50 & 0 & 0 \\
L2-1 & 50 & 2.36 & 10 \\
L2-2 & 50 & 7.07 & 30 \\
L2-3 & 50 & 11.80 & 50 \\
L3-0 & 100 & 0 & 0 \\
L3-1 & 100 & 2.36 & 10 \\
L3-2 & 100 & 7.07 & 30 \\
L3-3 & 100 & 11.80 & 50 \\
\hline
\end{tabular}

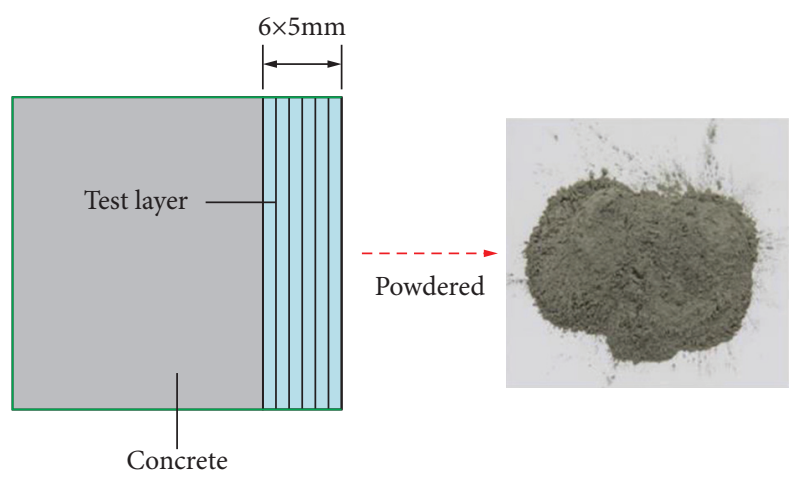

Figure 3: Concrete sampling for chloride content measurement.

corrosion) mass of the reinforcing steel bars was evaluated to establish the corrosion rate $\rho$ as

$$
\rho=\frac{\Delta m}{m}
$$

where $\Delta m$ is mass loss of the steel and $m$ is original mass of the steel.

\section{Results and Discussion}

3.1. Effect of Stray Current on Chloride Transport. Figure 4 shows the concentration of chloride ions under the stray current. The influence of stray current on the distribution of the chloride ion concentration in concrete can be observed. The chloride ion content of the concrete specimen under stray current on $1 \mathrm{~d}$ is shown in Figure 4(a). As with the increase of the stray current, the chloride ion content in concrete increased significantly. Then, the release and destabilization of bound chlorides were attributed to the stray current in the concrete, gradually resulting in an increase of the chloride ion content of concrete. Since the tortuosity of pores in the concrete, the impediment of chloride transport was enhanced with the increase of the depth, which caused the decrease of the chloride ion content.

The chloride ion content of the specimen under stray current in $7 \mathrm{~d}$ is shown in Figure 4(b). As compared with the 


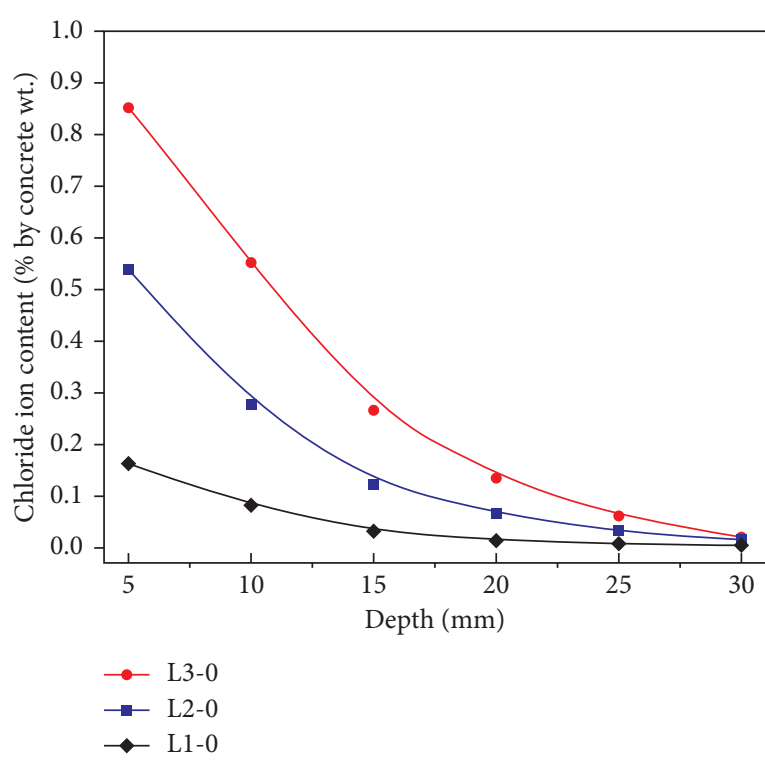

(a)

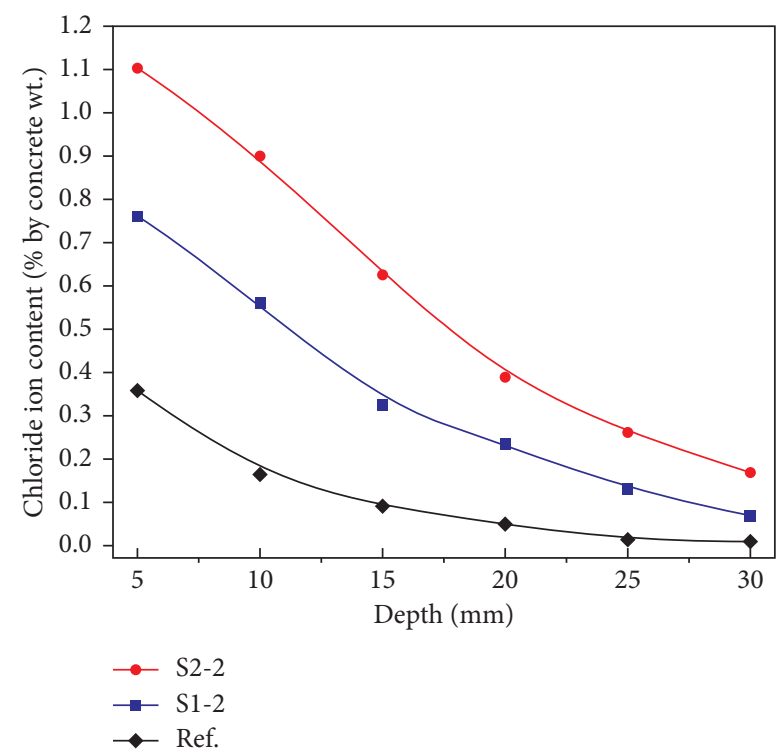

(b)

FIgure 4: Chloride profiles for concrete under stray current with different test times: (a) $1 \mathrm{~d}$ and (b) $14 \mathrm{~d}$.

measurements shown in Figure 4(a), the chloride transport to the depth of concrete increased surely with $7 \mathrm{~d}$, and the rate of chloride ion content growth is gradually accelerated until the distribution of chloride in concrete tends to be balanced.

\subsection{Effect of Stray Current and Compressive Loading on} Chloride Transport. To investigate the effect of stray current and sustained compressive loading on the chloride transport in concrete, the corrosion test of concrete under the combined action of stray current and sustained compressive loading was carried out. The observations of the front depth of chloride ion content in the concrete specimens under the action of sustained compressive loading and stray current are presented, as shown in Figure 5.

It can be seen from Figure 5 that if the stray current was constant, the chloride ion content in the concrete decreased with the increase of the stress level $\lambda$, when the stress level $\lambda \leq 30 \%$, although the degree of change was not obvious. On the contrary, the chloride ion content increases significantly with the increase of stress level $\lambda$ when stress level $\lambda>30 \%$. If the compressive stress level $\lambda$ is constant, the chloride ion content of concrete increased with the increase of stray current. According to the experimental data presented in Figure 5, the measured relationship between the apparent chloride ion diffusion coefficient $D_{\mathrm{a}}$ and the stress level $\lambda$ was obtained by the least squares method, and the fitting curves are plotted in Figure 6.

In Figure 6, the apparent chloride transport coefficient at a given current initially decreased with the increase of the compressive stress level $(0 \% \leq \lambda \leq 30 \%)$ and, on the contrary, began to increase beyond the stress level threshold $(\lambda>30 \%)$. It was mainly because the concrete was in the elastic stage under compressive stress lower than the threshold, and some pores and microcracks in concrete may be closed under compressive stress, which caused the decrease of porosity in concrete. When the compressive stress level was higher than the threshold, the damage of concrete began to increase rapidly with the developing microcracks and interconnecting pore systems, which result in an increase of the chloride transport in concrete. In our study, the compressive stress level $\lambda$ of approximately $30 \%$ was regarded as the stress level threshold at which the apparent chloride ion diffusion coefficient in the concrete unusually varied, corresponding to the development of microcracks in concrete. As the stray current was coupled with compressive loading, the apparent chloride ion diffusion in concrete was clearly increased, and the degree of increase was further more for the compressive stress level higher than $30 \%$. It was due to the acceleration effect of stray current on chloride which was amplified by the rapid cracking and interconnecting pores of concrete under compressive stress. It can be found that, for the short-term corrosion process, the influence of stray current on chloride transport in the concrete was more obvious than that of compressive stress levels. However, the synergism of them should not be ignored, as the change of pore structure and microcracks of concrete affected the acceleration of current to chloride transport.

3.3. Model Establishment and Verification of Chloride Transport. Generally, three main driving forces of ion transport are convection, diffusion, and migration [29, 30]. Therefore, the total chloride ion flux density can be expressed in the following form:

$$
J=J_{c}+J_{d}+J_{e}
$$

where $J_{\mathrm{c}}$ is the chloride ion flux density by convection, $J_{\mathrm{d}}$ is the chloride ion flux density by diffusion, and $J_{\mathrm{e}}$ is the chloride ion flux density by electro migration. 


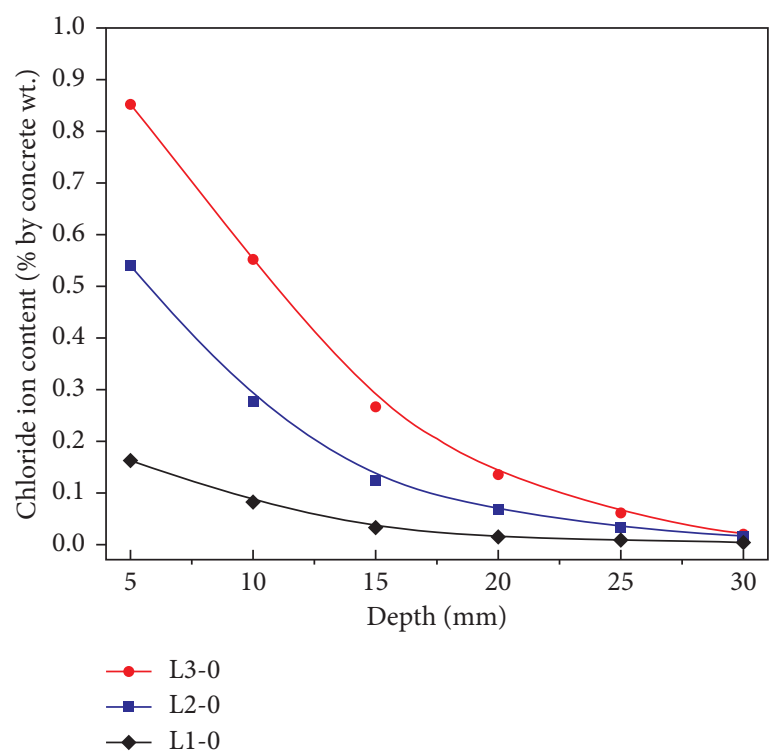

(a)
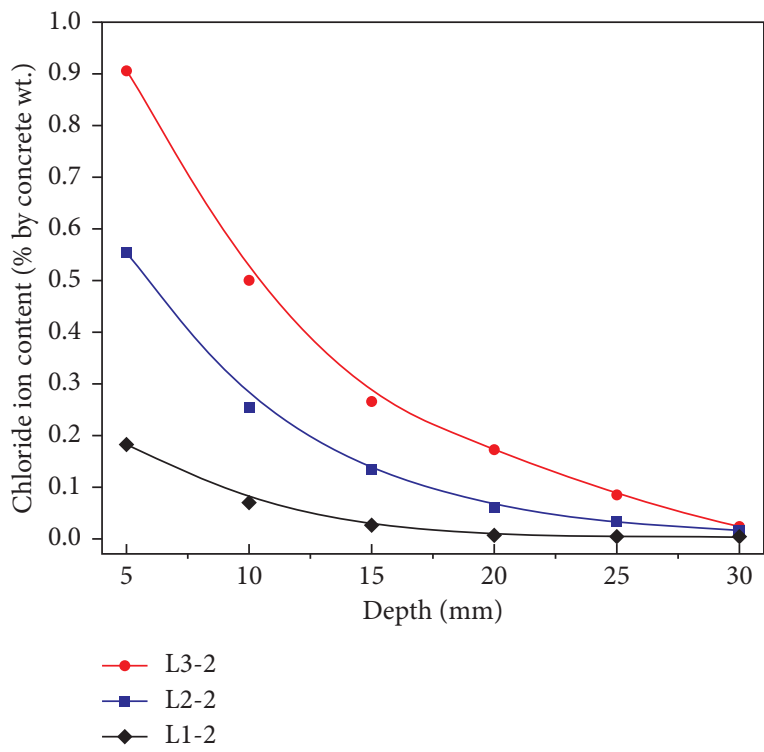

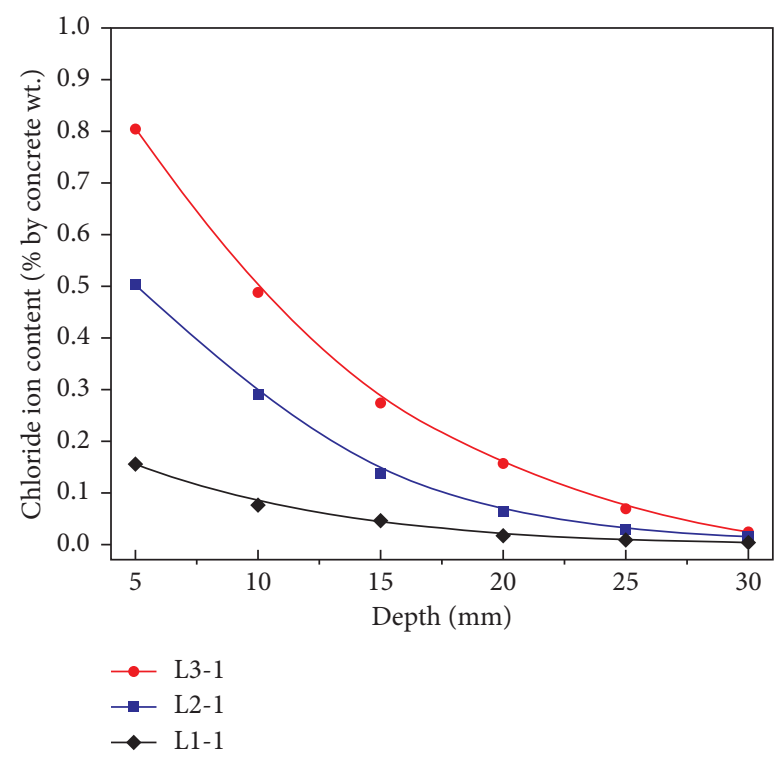

(b)

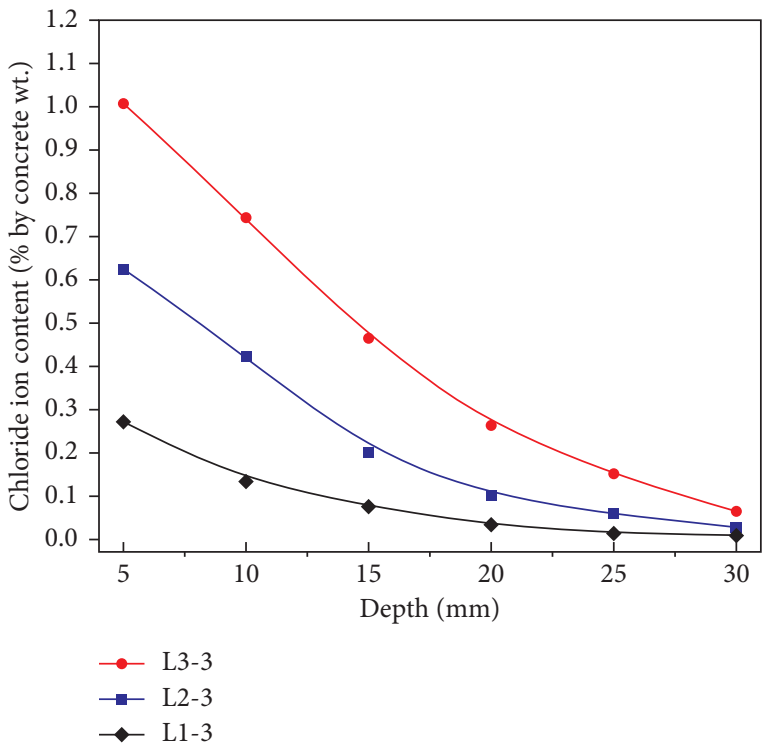

(d)

Figure 5: Chloride profiles for concrete under stray current with different stress levels: (a) $\lambda=0$. (b) $\lambda=10 \%$. (c) $\lambda=30 \%$. (d) $\lambda=50 \%$.

Based on Fick's law, the chloride ion flux density can be described as

$$
J_{d}=-D \nabla C,
$$

where $C$ is the total chloride ion content in concrete and $D$ is the chloride diffusion coefficient in concrete $\left(\mathrm{m}^{2} / \mathrm{s}\right)$.

Based on the Nernst-Planck equation, the chloride ion flux density by migration can be described as

$$
J_{\mathrm{e}}=\frac{-z \mathrm{FDC}}{\mathrm{RT}} \nabla \phi
$$

where $C$ is the total chloride content in concrete, $D$ is the chloride diffusion coefficient in concrete $\left(\mathrm{m}^{2} / \mathrm{s}\right), z$ is the valence of ions, $T$ is the temperature $(\mathrm{K}), F$ is the Faraday constant $(96,487 \mathrm{C} / \mathrm{mol}), R$ is the molar gas constant $(8.314 \mathrm{~J} /$
$\mathrm{K} / \mathrm{mol}$ ), and $\phi$ is the electric potential $(\mathrm{V})$. For the electric potential, Ohm's law is employed to analyse the electric potential $\phi$ by the current according to

$$
i=-r \nabla \phi \text {. }
$$

As considering the action of stray current and compressive loading with the other conditions (water-cement ratio, temperature, humidity, etc.) unchanged, the simplified model of the chloride diffusion coefficient in concrete based on the several studies [31-33] can be established as

$$
D_{E, L}=D \cdot f(\lambda) \text {. }
$$

In this paper, as the rate of chloride ions is greatly accelerated by stray current, the influence of convection on the chloride transport can be ignored [34]. Therefore, the 


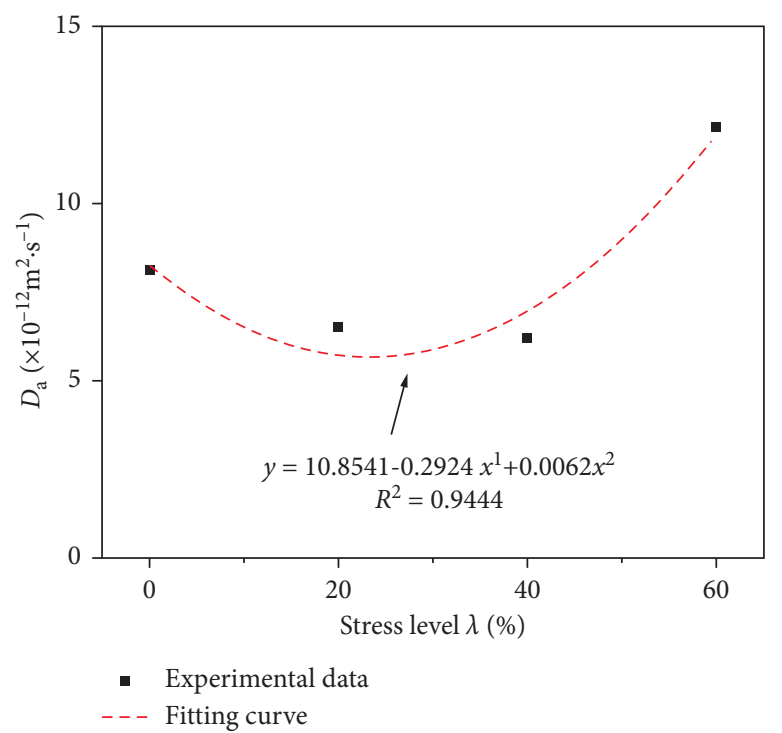

(a)

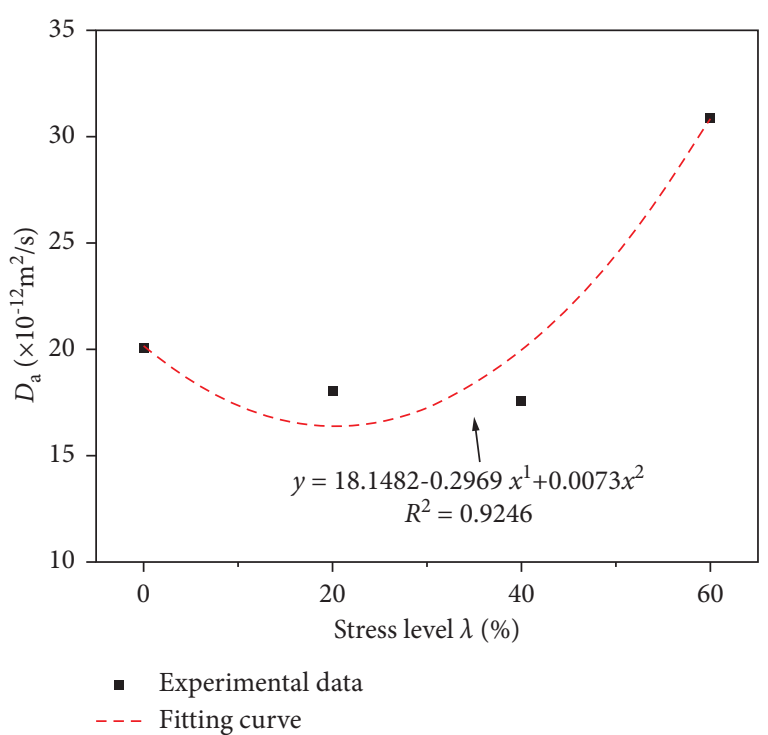

(b)

FIGURE 6: Apparent chloride transport coefficient in concrete with/without stray current: (a) $0 \mathrm{~mA}$. (b) $100 \mathrm{~mA}$.

total chloride ion flux density with the combined action of stray current and compressive loading can be described as

$$
J_{E, L}=\left(J_{d}+J_{e}\right) \cdot f(\lambda) \text {. }
$$

Substitution of equations (5)-(7) to (8) results in the following form:

$$
J_{E, L}=-\left(D \nabla C+\frac{z \mathrm{FDC}}{\mathrm{RT}} \nabla \phi\right) \cdot f(\lambda),
$$

where $f(\lambda)$ is the influence function on the chloride diffusion coefficient in concrete. According to the experimental data presented, it can be described as

$$
f(\lambda)=1+\alpha_{1} \cdot \lambda+\alpha_{2} \cdot \lambda^{2}
$$

where $\alpha_{1}$ and $\alpha_{2}$ are fitted parameters and $\lambda$ is the compressive stress level.

As various ions exist in the concrete pore solution and can exert effect on the chloride transport [35], by using the assumption that the concrete is a saturated pore medium and there are no chemical reactions between ionic species occurring in both liquid and solid phases, the following mass conservation for each individual ionic species involved in the concrete can be described as

$$
\frac{\partial C_{k}}{\partial t}=-\nabla J_{k}, \quad k=1, \ldots, N
$$

where $C_{k}$ is the concentration of the $k$ th ionic species, $t$ is the time, $J_{k}$ is the flux of the $k$ ionic species, and $N$ is the total number of the ionic species contained in the concrete. Diffusion and migration are treated as the major reason for ionic transport in this study; therefore, the ionic flux equation can be expressed as

$$
\frac{\partial C_{k}}{\partial t}=\nabla\left(D_{k} \nabla C_{k}\right)+\frac{z_{k} D_{k} F}{R T} \nabla\left(C_{k} \nabla \phi\right), \quad k=1, \ldots, N
$$

In reference to existing studies, the proposed model of chloride transport considering the effect of stray current and sustained compressive loading was solved by using the Galerkin weighted residual method and the Crank-Nicholson method [36-38]. Thus, the proposed model was validated by experimental data from the chloride transport in concrete for 1 day under stray current $(0$, $50 \mathrm{~mA}$, and $100 \mathrm{~mA}$ ) and sustained compressive stress level $\lambda$ (10\% and $50 \%)$.

Figure 7 shows the comparison between experimental data and numerical results by the chloride content in concrete. The experimental data and numerical result for L11 and L1-3 were regarded as a reference to the effect of stray current on chloride transport. It can be found that the numerical result of the proposed model was in good agreement with the experimental data of the chloride transport in concrete with the effect of stray current and sustained compressive loading. If the loading is other types or long-term loading, the model should be modified and verified to consider the damage of concrete with different loadings.

3.4. Model of Corrosion-Induced Crack. Considering that the chloride ion diffusion coefficient and corrosion rate in concrete are time-varying, the steel in the concrete will be undergo corrosion when the chloride ion concentration reaches a critical concentration. This paper chooses $1 \%$ as the critical chloride ion concentration $C_{0}$ [39], so the initial corrosion time $t_{0}$ can be described as 


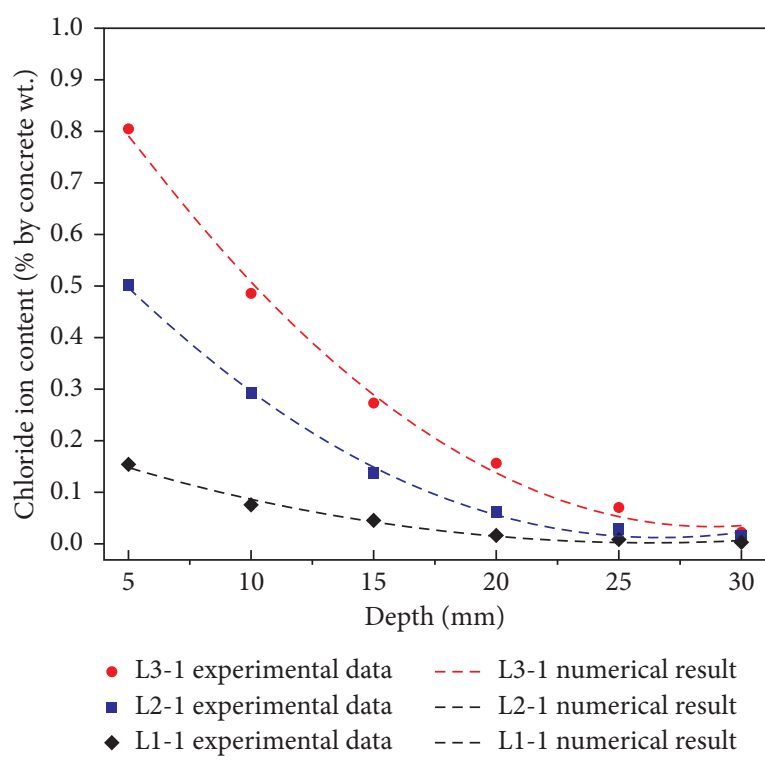

(a)

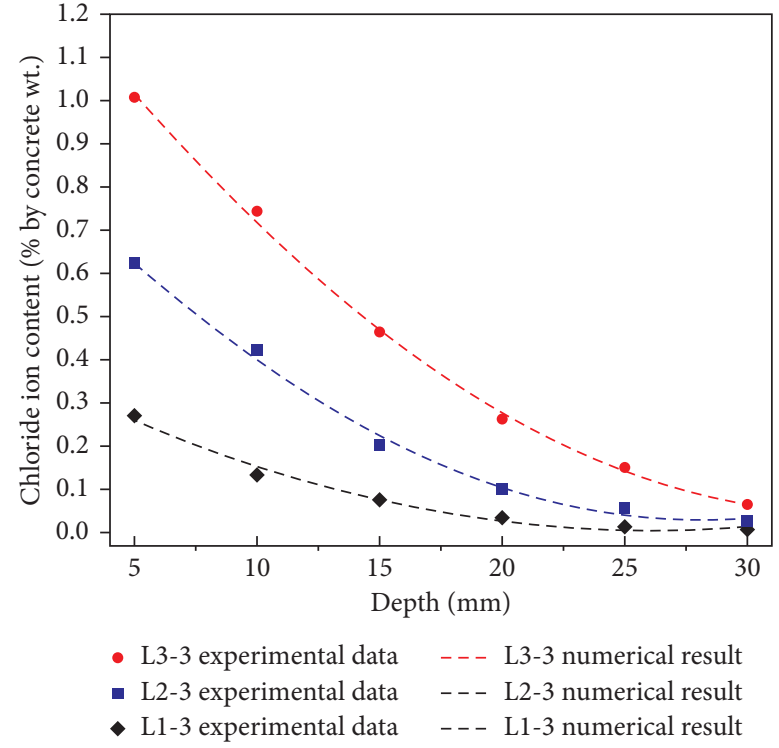

(b)

FIGURE 7: Comparison between the predicted and experimental chloride transport profiles under different compressive stress levels: (a) $\lambda=10 \%$. (b) $\lambda=50 \%$.

TABLE 4: Comparison between experimental and calculation values of average corrosion-induced cracking width $\left(w_{1}\right.$ is the test result and $w_{2}$ is the calculated result).

\begin{tabular}{lcccccc}
\hline$i(\mathrm{~mA})$ & $t($ day $)$ & $d(\mathrm{~mm})$ & $c(\mathrm{~mm})$ & $\rho(\%)$ & $w_{1}(\mathrm{~mm})$ & $w_{2}(\mathrm{~mm})$ \\
\hline 50 & 7 & 16 & 67 & 3.543 & 0.31 & 0.61 \\
50 & 14 & 16 & 67 & 9.626 & 0.287 \\
50 & 28 & 16 & 67 & 4.05 & 0.592 \\
100 & 7 & 16 & 67 & 6.947 & 0.93 & 0.78 \\
100 & 14 & 16 & 67 & 11.855 & 1.14 \\
100 & 28 & 16 & & & 0.454 \\
\hline
\end{tabular}

$$
t_{0}=\frac{x^{2}}{4 \operatorname{Derf}^{-1}\left(1-C_{0} / C_{s}\right)} a,
$$

where $x$ is the distance from the reinforcement surface to concrete surface and $C_{s}$ is the chloride ion concentration on the concrete surface.

After corrosion time $t$, the average loss of diameter of the steel $\Delta d$ can be described as [40]

$$
\Delta d(t)=0.0232\left(t-t_{0}\right) i .
$$

The corrosion rate of steel $\rho$ can be expressed as

$$
\rho(t)=1-\left[1-2 \frac{0.0232\left(t-t_{0}\right) i}{d}\right]^{2},
$$

where $d$ is diameter of steel.

Considering the cracking mode and the crack width on the surface of the protective layer under steel corrosion rust expansion, the relationship between crack width $w$ and corrosion rate $\rho$ is proposed as [41]

$$
w=-0.002+(0.165-0.006 c+0.007 d) \rho,
$$

where $c$ is thickness of the concrete cover.
The cracks of specimens in the corrosion test were observed and counted; then, the corroded steel was cleaned and weighed to calculate the corrosion rate. The results are shown in Table 4.

Combined with the calculation model in this paper, the crack width of the test specimen was theoretically analysed. Table 4 shows the comparison between experimental results and numerical results of corrosion-induced cracking width. When the test current was $50 \mathrm{~mA}$, the maximum relative error between the theoretical value and the experimental value was $9.24 \%$, and the average relative error was $4.32 \%$. When the test current was $100 \mathrm{~mA}$, the maximum relative error between the theoretical value and the experimental value was $11.75 \%$, and the average relative error was $5.68 \%$. There was an error between the theoretical value and the experimental value, which may be caused by the uncertainty of the properties of concrete and the error in the measurement process of corrosion rate and crack width. On the whole, the error between the theoretical value and the experimental value was acceptable.

The fitting relationship between corrosion rate and crack width can be obtained from Figure 8 . It can be seen that, with the increase of stray current, the cracking time of concrete 


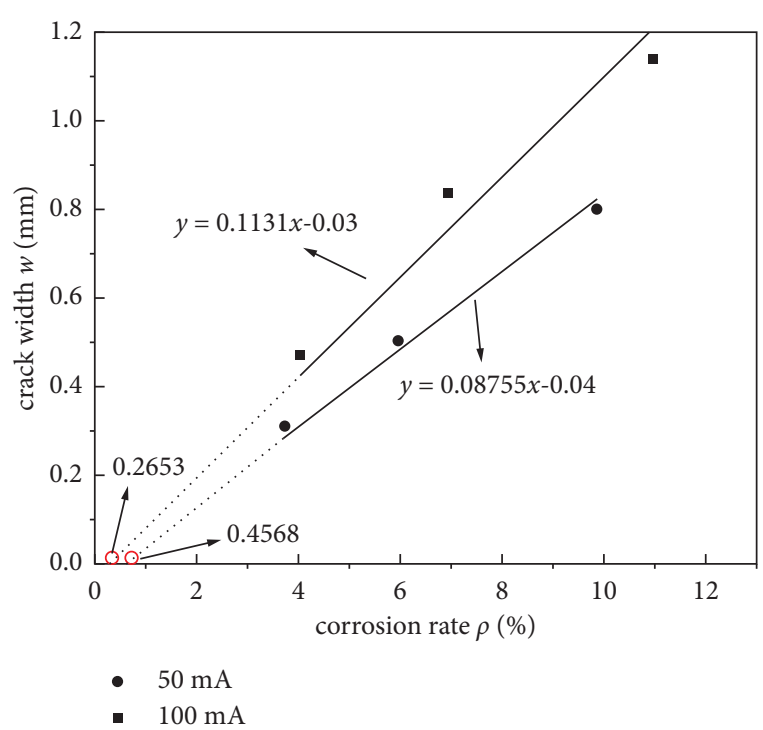

FIGURE 8: Relationship between corrosion-induced cracking width and corrosion rate.

will be advanced and the cracking speed will be accelerated. This may be due to the existence of stray current, which accelerates the steel corrosion in the concrete and the precipitation of calcium ions in concrete, resulting in cracking of concrete more easily.

\section{Conclusions}

Considering the corrosion characteristics of the subway structure, two experiments were conducted in this study to investigate the effects of stray current and sustained compressive loading on the chloride transport in concrete. From the experimental results of this work, the following conclusions can be drawn:

(1) The experimental results for the specimens indicated that chloride transport in concrete embedded with steel was more efficient than that in plain concrete. It was mainly because of the accumulation of chloride ions near the steel, resulting in $\mathrm{Ca}(\mathrm{OH})_{2}$ and C-S-H to decompose faster near the steel to maintain the balance of the ion concentration under the action of stray current.

(2) As with the acceleration effect of stray current and the threshold effect of chloride transport under compressive loading on chloride transport, it can be found that if the compressive loading was higher than the loading threshold, the chloride transport increased with the combined action was higher than that of any single action.

(3) Based on the experimental results, a numerical model for chloride transport in concrete with the effect of stray current and compressive loading was proposed and verified. The comparison indicated that the chloride distribution predicted by the proposed model was in good agreement with the experimental results.

\section{Data Availability}

No data were used to support this study.

\section{Conflicts of Interest}

The authors declare that there are no conflicts of interest regarding the publication of this paper.

\section{Acknowledgments}

The authors acknowledge the support of Scientific Research Projects of Beijing Subway Operation Co., Beijing Jiaotong University, and National Natural Science Foundation of China (NSFC), Grant no. 51727813.

\section{References}

[1] F. Brichau, J. Deconinck, and T. Driesens, "Modeling of underground cathodic protection stray currents," Corrosion, vol. 52, no. 6, pp. 480-488, 1996.

[2] S. Yang and X. Yang, "Evaluation of stray current corrosion resistance of concrete in metro construction," Frontiers of Architecture and Civil Engineering in China, vol. 2, no. 3, pp. 246-252, 2008.

[3] A. O. S. Solgaard, M. Carsana, M. R. Geiker, A. Küter, and L. Bertolini, "Experimental observations of stray current effects on steel fibres embedded in mortar," Corrosion Science, vol. 74, pp. 1-12, 2013.

[4] Y. Hong, Z. Li, G. Qiao, and J. Ou, "Numerical simulation and experimental investigation of the stray current corrosion of viaducts in the high-speed rail transit system," Construction and Building Materials, vol. 157, pp. 416-423, 2017.

[5] R. A. Patel, Q. T. Phung, and S. C. Seetharam, "Diffusivity of saturated ordinary Portland cement-based materials: a critical review of experimental and analytical modelling approaches," Cement and Concrete Research, vol. 90, pp. 52-72, 2016.

[6] M. Siegwart, J. F. Lyness, and B. J. McFarland, "Change of pore size in concrete due to electrochemical chloride extraction and possible implications for the migration of ions," Cement and Concrete Research, vol. 33, no. 8, pp. 1211-1221, 2003.

[7] H. G. Midgley and J. M. Illston, "The penetration of chlorides into hardened cement pastes," Cement and Concrete Research, vol. 14, no. 4, pp. 546-558, 1984.

[8] P. Zhang, D. Hou, Q. Liu, Z. Liu, and J. Yu, "Water and chloride ions migration in porous cementitious materials: an experimental and molecular dynamics investigation," Cement and Concrete Research, vol. 102, pp. 161-174, 2017.

[9] A. K. Suryavanshi and R. N. Swamy, "Influence of penetrating chlorides on the pore structure of structural concrete," $\mathrm{Ce}$ ment, Concrete and Aggregates, vol. 20, pp. 169-179, 1998.

[10] A. Aghajani, M. Urgen, and L. Bertolini, "Effects of DC stray current on concrete permeability," Journal of Materials in Civil Engineering, vol. 28, no. 4, Article ID 4015177, 2016.

[11] J. Tritthart, K. Pettersson, and B. Sorensen, "Electrochemical removal of chloride from hardened cement paste," Cement and Concrete Research, vol. 23, no. 5, pp. 1095-1104, 1993.

[12] J. N. Enevoldsen, C. M. Hansson, and B. B. Hope, "Binding of chloride in mortar containing admixed or penetrated chlorides," Cement and Concrete Research, vol. 24, no. 8, pp. 1525-1533, 1994. 
[13] M. Castellote, C. Andrade, and C. Alonso, "Chloride-binding isotherms in concrete submitted to non-steady-state migration experiments," Cement and Concrete Research, vol. 29, no. 11, pp. 1799-1806, 1999.

[14] J. M. Loche, A. Ammar, and P. Dumargue, "Influence of the migration of chloride ions on the electrochemical impedance spectroscopy of mortar paste," Cement and Concrete Research, vol. 35, no. 9, pp. 1797-1803, 2005.

[15] Q. T. Phung, N. Maes, D. Jacques, G. De Schutter, and G. Ye, "Investigation of the changes in microstructure and transport properties of leached cement pastes accounting for mix composition," Cement and Concrete Research, vol. 79, pp. 217-234, 2016.

[16] S. D. Abyaneh, H. S. Wong, and N. R. Buenfeld, "Simulating the effect of microcracks on the diffusivity and permeability of concrete using a three-dimensional model," Computational Materials Science, vol. 119, pp. 130-143, 2016.

[17] Z. Wang, Q. Zeng, L. Wang, Y. Yao, and K. Li, "Corrosion of rebar in concrete under cyclic freeze-thaw and Chloride salt action," Construction and Building Materials, vol. 53, pp. 40-47, 2014.

[18] H. L. Wang, J. G. Dai, X. Y. Sun, and X. L. Zhang, "Characteristics of concrete cracks and their influence on chloride penetration," Construction and Building Materials, vol. 107, pp. 216-225, 2016.

[19] Q. F. Liu, J. Yang, J. Xia, and D. Easterbrook, L. Li, L. Y. Li, and X. Y. Lu, A numerical study on chloride migration in cracked concrete using multi-component ionic transport models," Computational Materials Science, vol. 99, pp. 396-416, 2015.

[20] S. W. Yoo and S. J. Kwon, "Effects of cold joint and loading conditions on chloride diffusion in concrete containing GGBFS," Construction and Building Materials, vol. 115, pp. 247-255, 2016.

[21] L. Jin, R. Zhang, X. Du, and Y. Li, "Multi-scale analytical theory of the diffusivity of concrete subjected to mechanical stress," Construction and Building Materials, vol. 95, pp. 171-185, 2015.

[22] C. C. Lim, N. Gowripalan, and V. Sirivivatnanon, "Microcracking and chloride permeability of concrete under uniaxial compression," Cement and Concrete Composites, vol. 22, no. 5, pp. 353-360, 2000.

[23] A. T. Djerbi, S. Bonnet, A. Khelidj, and V. B. Baroghel, "Effect of uniaxial compressive loading on gas permeability and chloride diffusion coefficient of concrete and their relationship," Cement and Concrete Research, vol. 52, pp. 131-139, 2013.

[24] M. Hoseini, V. Bindiganavile, and N. Banthia, "The effect of mechanical stress on permeability of concrete: a review," Cement and Concrete Composites, vol. 31, no. 4, pp. 213-220, 2009.

[25] Gb/T. 50082-2009, Standard for Test Method of Long-Term Performance and Durability of Ordinary Concrete, Chinese Standard Institution Press, Beijing, China, 2009.

[26] C. A. Charalambous, P. Aylott, and D. Buxton, "Stray current calculation and monitoring in DC mass-transit systems: interpreting calculations for real-life conditions and determining appropriate safety margins," IEEE Vehicular Technology Magazine, vol. 11, no. 2, pp. 24-31, 2016.

[27] G. Lucca, "Estimating stray current interference from DC traction lines on buried pipelines by means of a Monte Carlo algorithm," Electrical Engineering, vol. 97, no. 4, pp. 277-286, 2015.

[28] Gb/T. 176-2017, Methods for Chemical Analysis of Cement, Chinese Standard Institution Press, Beijing, China, 2017.
[29] H. Chu, T. Wang, M. Z. Guo et al., "Effect of stray current on stability of bound chlorides in chloride and sulfate coexistence environment," Construction and Building Materials, vol. 194, pp. 247-256, 2019.

[30] S. Goto and D. M. Roy, "Diffusion of ions through hardened cement pastes," Cement and Concrete Research, vol. 11, no. 56, pp. 751-757, 1981.

[31] B. Díaz, X. R. Nóvoa, and M. C. Pérez, "Study of the chloride diffusion in mortar: a new method of determining diffusion coefficients based on impedance measurements," Cement and Concrete Composites, vol. 28, no. 3, pp. 237-245, 2006.

[32] C. M. Aldea, S. P. Shah, and A. Karr, "Permeability of cracked concrete," Materials and structures, vol. 32, no. 5, pp. 370-376, 1999.

[33] A. Ababneh, F. Benboudjema, and Y. Xi, "Chloride penetration in nonsaturated concrete," Journal of Materials in Civil Engineering, vol. 15, no. 2, pp. 183-191, 2003.

[34] H. Wang, C. Lu, W. Jin, and Y. Bai, "Effect of external loads on chloride transport in concrete," Journal of Materials in Civil Engineering, vol. 23, no. 7, pp. 1043-1049, 2011.

[35] M. M. Jensen, K. D. Weerdt, B. Johannesson, and M. R. Geiker, "Use of a multi-species reactive transport model to simulate chloride ingress in mortar exposed to $\mathrm{NaCl}$ solution or sea-water," Computational Materials Science, vol. 105, pp. 75-82, 2015.

[36] J. Němeček, J. Kruis, T. Koudelka, and T. Krejčí, "Simulation of chloride migration in reinforced concrete," Applied Mathematics and Computation, vol. 319, pp. 575-585, 2018.

[37] J. Bao and L. Wang, "Combined effect of water and sustained compressive loading on chloride penetration into concrete," Construction and Building Materials, vol. 156, pp. 708-718, 2017.

[38] J. Xia and L. Y. Li, "Numerical simulation of ionic transport in cement paste under the action of externally applied electric field," Construction and Building Materials, vol. 39, pp. 51-59, 2013.

[39] M. C. Alonso and M. Sanchez, "Analysis of the variability of chloride threshold values in the literature," Materials and Corrosion, vol. 60, no. 8, pp. 631-637, 2009.

[40] M. G. Stewart and D. V. Rosowsky, "Time-dependent reliability of deteriorating reinforced concrete bridge decks," Structural Safety, vol. 20, no. 1, pp. 91-109, 1998.

[41] J. Zhang, X. Ling, and Z. Guan, "Finite element modeling of concrete cover crack propagation due to non-uniform corrosion of reinforcement," Construction and Building Materials, vol. 132, pp. 487-499, 2017. 